\title{
Lentivirus-Mediated Gene Silencing of Lymphocyte Function-Associated Antigen 1 Inhibits Apoptosis of Hippocampal Neurons in Rats with Acute Cerebral Ischemia After Cerebral Lymphatic Blockage
}

Jin-Lu Yua Chao Li ${ }^{\mathrm{b}} \quad \mathrm{Li}^{\mathrm{a}} \mathrm{He} \mathrm{Che}^{\mathrm{c}} \quad \mathrm{Ning} \mathrm{Xu}^{\mathrm{a}}$

${ }^{a}$ Department of Neurosurgery, the First Hospital of Jilin University, Changchun, bepartment of Neurology, the First Hospital of Jilin University, Changchun, 'Department of Infectious Diseases, the First Hospital of Jilin University, Changchun, P. R. China 